\title{
INTRODUÇÃO AO CURRÍCULO E DIVERSIDADE NO CENÁRIO BRASILEIRO
}

BASTOS, Manoel de Jesus ${ }^{1}$

BASTOS, Manoel de Jesus. Introdução ao Currículo e Diversidade no Cenário Brasileiro. Revista Científica Multidisciplinar Núcleo do Conhecimento. Ano 02, Ed. 01, Vol. 14, pp. 22-30 Janeiro de 2017. ISSN: 2448-0959

\section{RESUMO}

No contexto social em que vivemos há uma diversidade muito grande de currículos, contendo cada um à sua imensurável importância para o desenvolvimento do setor no qual está inserido. No espaço educacional ele apresenta-se como dispositivo orientador dos projetos políticos-pedagógicos, considerando a importância da união de forças pedagógicas com intenções de educar. A diversidade cultural é a principal responsável pela construção e aprimoramento contínuo do contexto político, cultural e social. É através da interação mútua de indivíduos que constitui-se a fusão de conhecimentos, costumes e saberes. A prática curricular torna-se necessária aos avanços crescentes na cultura política, pedagógica e social, para a consolidação de uma sociedade justa, igualitária e democrática.

Palavras-Chave: Diversidade, Pedagógica, Cultural, Social, Currículo.

\section{INTRODUÇÃO}

Os questionamentos a respeito de currículos pedagógicos, que antes eram entendidos como conteúdos a serem ensinados e assimilados pelos alunos, agora explicita que que esses passam a ser uma construção e apuração de conhecimentos didáticos

\footnotetext{
${ }^{1}$ Formado em Normal Superior pela UESPI (Universidade Estadual do Piauí), Pósgraduado em Supervisão Escolar pela Faculdade de Teologia Hokemãh - Fateh e Mestrando em Educação pela Anne Sullivan University.
} 
produzidos nas áreas sociais, culturais, políticas, intelectuais e pedagógicas. Conhecimentos e práticas, uma vez indissociáveis, devem estar expostos às dinâmicas e as novas interpretações que surgem em cada contexto histórico.

Há uma diversidade de currículos no contexto social, cabendo cada um refletir sobre a sua imensurável importância para o desenvolvimento de cada setor. No espaço educacional o currículo apresenta-se como tema central orientador nos projetos políticos-pedagógicos, onde faz menção que considerar currículo é, ao mesmo tempo, unir forças pedagógicas com intenções de educar.

A prática curricular torna-se necessária para a idealização de uma sociedade que apresenta avanços crescentes na cultura política, pedagógica e social, contribuindo para formação de uma sociedade justa, igualitária e democrática. A parceria entre todos os componentes da comunidade, para a busca de objetivos comuns, é que vai consolidar a efetivação de resultados satisfatórios em um grupo social.

As indagações curriculares visam contribuir com as suas dinâmicas embasadas em teorias, cujas experiências, tem apontado, visivelmente, resultados crescentes e aceitáveis nas áreas da formação humana. E a quem cabe essa tarefa de indagações? Todos os profissionais que fazem parte de determinada área pedagógica, devem ter a incumbência de contribuir com a sua parcela de esforço com o intuito de alcançar os resultados almejados coletivamente, ou seja, o currículo é o exercício coletivo que superará estilos fragmentados do processo do ensino-aprendizagem.

Contudo, a diversidade de currículo desdobra-se em meio as muitas etapas da educação, desde a educação infantil à universidade. Essa diversidade cultural deve ser entendida como a construção ou preservação histórica, social e cultural das diferenças. Essas diferenças são construídas e condicionadas pelos indivíduos à proporção que as observam e se adaptam ao meio social.

Seria impossível a obtenção de bons resultados, em determinada tarefa, se não fosse levado em conta a importância dos esforços coletivos. Cada componente do grupo é, analogicamente, um elo que dá robustez a corrente geradora do desenvolvimento 
curricular, por fazer parte da diversidade cultural e por se fazer presente no cotidiano pedagógico nas mais diferentes idades, culturas e etnias raciais. Todas essas diferenças são desafios que se enfrenta nos campos da educação escolar, da educação infantil à superior.

E por se fazer presente em toda a sociedade, a educação é um processo democrático da experiência humana. É no contexto das relações humanas que se constrói, hibridizadamente, os conhecimentos, as identidades e os valores. Contudo, o desenvolvimento biológico e o das práticas culturais presentes nas sociedades são indispensáveis às transformações do ser humano.

\section{REFLEXÕES SOBRE A DIVERSIDADE CULTURAL}

Os seres humanos são constituídos por um processo onde apresentam ora semelhanças, ora diferenças ao longo de sua história cultural, cabendo cada um aprender a conviver com essas diferenças. A postura do indivíduo não deve desenvolver hierarquias nas diferenças e compreender que dentro do grupo social ninguém é melhor ou pior que o outro. As diferenças que apresentam no físico, nas concepções e nas tomadas de decisões de cada pessoa, refletem-se na igualdade de direitos.

A diversidade cultural é a principal responsável pela construção e aprimoramento contínuo do contexto político, cultural e social. É através da interação mútua de indivíduos que constitui-se a fusão de conhecimentos, costumes e saberes. Não há nenhuma identidade construída isoladamente, ela é negociada ao longo da vida por meio do diálogo e do experimento. As relações dialógicas são imprescindíveis entre indivíduos para a compreensão, o conhecimento e o desenvolvimento social.

Cada contexto pode apresentar certa diversidade cultural onde as interpretações também são variadas, ou seja, as características ou as formas como são vistas vão depender do lócus ocupado pela sociedade e da relação existente entre as pessoas. Toda sociedade constitui-se de contextos socioeconômicos, históricos e políticos onde há a presença das identidades, das desigualdades e das diferenças. Os grupos 
humanos, considerados diferentes, destacam-se, cada vez mais, nas sociedades em que estão inseridos, exigindo tratamento justo e igualitário para todos.

A diversidade curricular está presente em todos os setores sociais, e como faz parte do acontecer humano, cabe a escola trabalhá-la, uma vez que é nela que que as diferentes presenças se encontram. Por isso essa diversidade deve estar inserida nos currículos escolares onde há várias concepções, posicionamentos e pontos de vistas teóricos. Os currículos apresentam aspectos políticos, considerados como atividades produtivas no meio social.

Para Silva,

as narrativas contidas no currículo, explícita e implicitamente, corporificam noções particulares sobre conhecimento, sobre formas de organização da sociedade, sobre os diferentes grupos sociais. Elas dizem qual conhecimento é legítimo, quais formas de conhecer são válidas e quais não o são, o que é certo e o que é errado, o que é moral e o que é imoral, o que é bom e o que é mau, o que é belo e o que é feio, quais vozes são autorizadas e quais não são (Silva, 1995, p. 195).

No entanto, há uma necessidade acentuada dos profissionais da educação saírem do comodismo e da inércia para cumprirem com a tarefa pedagógica mediante a diversidade cultural com que se depara constantemente. As práticas docentes precisam explicitar as riquezas contidas nas identidades e nas diversidades culturais encontradas nas escolas e na sociedade, superando as concepções provindas dessas culturas. Defende-se que a diversidade cultural esteja inserida nos currículos para facilitar a compreensão das causas econômicas, sociais e políticas.

É inadmissível que em pleno século XXI, onde é observável os avanços científicos e tecnológicos, exista tamanha discrepância entre valores humanos, onde há a presença da desigualdade e da discriminação social. A sociedade tem produzido diversos conhecimentos que ainda não foram incorporados nos currículos, principalmente no pedagógico. Portanto, a necessidade exige a incorporação de certos conhecimentos que explicitam sobre o processo histórico das diferenças e das 
desigualdades, nos currículos, para a superação dos problemas escolares e da diversidade.

Considera-se como sujeitos centrais de uma ação educativa, os educandos, para serem articuladores de certos movimentos sociais em prol do direito às diferenças e à diversidade. É no seio da instituição escolar e do bojo nuclear da família que os aspectos da diversidade cultural devem ser trabalhados com intenções de promover uma inter-relação convergente que sinalize a equidade social, de modo que, as características tanto locais quanto regionais, como os costumes, a cultura a sexualidade dentre outros, tornem-se itens diversificadores do currículo.

A luta em torno das modalidades educacionais e das pessoas com deficiência tem apresentado mudanças significativas na legislação, na revisão de propostas curriculares, nos processos de formação docente e, principalmente, nas políticas públicas, ao tempo em que tem surgido indagações à respeito dos conhecimentos produzidos pelos movimentos sociais e o conhecimento científico. A relação entre conhecimento e currículo exige um exercício pedagógico de reconhecer os saberes produzidos pela comunidade e pelos movimentos sociais, tendo em vista que a sua importância tem passado despercebida, resultando no desperdício da experiência social.

\section{DIVERSIDADE E ÉTICA CURRICULAR}

Reconhecer a diversidade curricular, significa compreender o nosso direcionamento no processo da formação humana que acontece em um absoluto contexto político, social, cultural e histórico. É nesse contexto que se constrói as representações, os valores e as identidades tanto individuais, quanto sociais. No ramo da pedagogia, reconhecer o professor e o aluno como verdadeiros sujeitos é, ao mesmo tempo, considerá-los como sujeitos éticos.

Contudo, não se deve negar a importância do conhecimento escolar, mas contribuir para a eliminação dos equívocos históricos escolar que se desencadeiam nos centros 
educacionais, uma vez que ele é o eixo norteador que viabilizará o pleno desenvolvimento humano.

Para Amauri Carlos Ferreira,

a ética é referência para que a escolha do sujeito seja aceita como um princípio geral que respeite e proteja o ser humano no mundo. Nesse sentido, o ethos, como costume, articula-se às escolhas que o sujeito faz ao longo da vida. A ética fundamenta moral, ao expressar a sua natureza reflexiva na sistematização das normas (FERREIRA, 2006, p. 32).

$\mathrm{Na}$ verdade, a relação existente entre diversidade e ética são práticas e políticas que orientam o respeito e a superação dos preconceitos, das discriminações e das diferenças. A exemplo, uma educação igualitária para negros, deficientes, índios, quilombolas além de outros. As instituições regulares devem incluir nos seus currículos os alunos com deficiências, visando a sua efetiva integração na vida em sociedade. (LDB, artigo 59, IV, p. 34).

A diversidade deve ser compreendida como a construtora histórica, cultural, social e equilibradora das diferenças, uma vez que ela ultrapassa todas as características da vida, observáveis explicitamente, como é o caso das pessoas com deficiência. Talvez não fosse o bastante incluí-las no ensino regular, se não realizasse, previamente, um processo reeducativo do olhar e das práticas, a fim de superar estereótipos que empecilham as potencialidades dos sujeitos. Apesar dos avanços observados nas políticas de inclusão, nos últimos anos, há, ainda, sinais perversos de discriminação e dificuldades à educação inclusiva.

Admite-se que há uma carência gigantesca de inclusão de toda diversidade, sobretudo dos deficientes nas instituições educacionais, nos currículos, nas organizações, nos processos avaliativos e em todo processo do ensinoaprendizagem. 


\section{CURRÍCULO E DESENVOLVIMENTO}

Por ser o currículo um conjunto de esforços pedagógicos, com intenções de viabilizar o desenvolvimento educacional, cabe, portanto, a atenção para a consolidação íntegra, das autoridades, dos gestores, dos professores, dos servidores, dos pais de alunos e dos alunos. É necessário que haja essa compreensão coletiva deixando, assim, de sobrecarregar os professores, achando que a tarefa "escolarizar" seja simplesmente sua. O desenvolvimento de um trabalho pedagógico só se efetivará a partir do momento em que toda a comunidade se envolver.

Todavia, para que um trabalho pedagógico avance com eficácia é preciso que haja um conjunto de preocupações voltadas à reflexões para posteriores ações norteadoras e a busca de sua qualidade. Não poderia haver desenvolvimento em determinada tarefa se não fosse levado em conta uma reflexão aprofundada. O educador é um grande artífice no processo curricular para que estes materializem-se nas escolas.

Documentos oficiais como as Diretrizes Curriculares Nacionais da Educação Básica, a Lei de Diretrizes e Bases da Educação Nacional, o Plano Nacional de Educação além de outros, tem subsidiado meios que favorecem a compreensão e o comprometimento de toda a comunidade escolar. Isso porque somente por intermédio do currículo, haverá melhoria nos resultados pedagógicos.

Apesar da nomenclatura "currículo" ser utilizada na indicação de efeitos projetados pelas instituições escolares em acordo com toda a comunidade, ele pode também ser considerado como algo organizador do processo: organização de espaço/tempo, distribuição dos alunos por turno/turma, arrumação das carteiras etc. Enfim, não importa a maneira como ele é adotado, desde que a sua importância se evidencie no processo educativo escolar.

Admite-se que a escola é o espaço específico onde ocorre a hibridização de culturas e de conhecimentos. Não se trata, de modo algum, de substituir um conhecimento por 
outro e sim possibilitar aos estudantes a compreensão mútua das relações envolvidas na hierarquização manifestadora das culturas e dos saberes.

Para Moreira e Candau,

a escola sempre teve dificuldade em lidar com a pluralidade e a diferença. Tende a silenciá-las e neutralizá-las. Sente-se mais confortável com a homogeneização e a padronização. No entanto, abrir espaços para a diversidade, a diferença e para o cruzamento de culturas constitui o grande desafio que está chamada a enfrentar (Moreira e Candau, 2003, p. 161).

Entende-se que a relevância do currículo se dá a partir do momento em que ele possibilita nas pessoas a capacidade de compreender o verdadeiro papel que todos devem desempenhar para a efetivação da mudança imediata no contexto social. Nessa perspectiva, o currículo é uma ferramenta que relaciona escola e sociedade, saberes e práticas socialmente construídos. No âmbito escolar o currículo proporciona a produção de diferentes saberes derivados do multiculturalismo ali existente. São esses saberes que constroem o currículo formal e constitui o conhecimento escolar hibridizado em sala de aula.

Embora tenha se discutido bastante a respeito da importância e imprescritabilidade do currículo pedagógico, o processo de descontextualização ainda faz-se presente no cotidiano do ensino empecilhando, de certa forma, no desenvolvimento do ensinoaprendizagem. Esse trabalho descontextualizado trará, como consequências, a perda de sentido dos conhecimentos distintos, existentes no âmbito escolar. Em outras palavras, a descontextualização dos conhecimentos desfavorecem um trabalho pedagógico reflexivo e uma aprendizagem significativa.

O currículo oferece um conjunto de práticas que possibilitam a interação entre as identidades sociais e culturais. É uma ferramenta de suma importância no processo construtivo da identidade e socialização do indivíduo. O espaço curricular pedagógico evidencia a consolidação da diversidade e da pluralidade cultural a que se vivencia no mundo contemporâneo. 
O currículo escolar é também um espaço onde, além de hibridizar conhecimentos, permeiam as críticas culturais, abrindo portas às diferentes manifestações das culturas popular e erudita. O que se espera é que a cultura de cada membro da comunidade escolar possa, de fato, interagir com outras manifestações, assimilando as suas diversidades.

\section{CONSIDERAÇÕES FINAIS}

Por ser o currículo um dispositivo educativo que representa uma hibridização de conhecimentos e valores éticos, culturais e sociais, ele precisa ser proposto pelo trabalho pedagógico, uma vez que educação e currículo devem ser vistos e considerados como ferramentas indispensáveis ao desenvolvimento do processo social e cultural. O currículo deve ser implementado como documento que contenha em suas páginas as mais diversificadas proposições de ideias, além dos esforços individuais e coletivos com almejos no desenvolvimento do processo formativo do indivíduo.

Cabe as instituições pedagógicas, por meio de suas ações, explicitar aos seus educandos que os acontecimentos são inevitáveis e que precisam ser questionados e modificados de acordo às necessidades dos educandos. Esses questionamentos devem provocar certas tensões no sentido de desafiar o existente, como diz (Moreira, 1999), podem não mudar o mundo, mas podem permitir que o aluno possa compreendê-lo melhor.

Nesse sentido, todos os profissionais da área pedagógica devem posicionarem-se, politicamente, comprometendo-se com estudos e pesquisas, para situarem-se frente a uma vasta engrenagem de problemas, econômicos, socioculturais, políticos e ambientais que aparecem como desafios, desconhecendo os limites entre as classes sociais. O esforço coletivo ou esforço curricular torna-se necessário para propiciar ao aluno uma maior compreensão do mundo no qual estão inseridos. Sem esse esforço a proposição de alternativas viáveis, resultantes dessas instigações e reflexões, seriam impossíveis. 
Portanto, para seu efeito consolidado, o currículo deve tornar-se em cada escola um espaço não só de pesquisas mas um mesclado de ideias e saberes. Nesse processo poderá ocorrer o aperfeiçoamento do desempenho profissional, a compreensão mútua e o engajamento na luta cotidiana para melhorá-lo.

$\mathrm{Na}$ complexidade desse processo, a comunidade responsável pelo seu desenvolvimento deve ser despertada com o intuito de adequação do espírito de pesquisa, da busca dos ideais, do aprendendizado, da contribuição e do reconhecimento das coisas novas.

\section{REFERÊNCIAS}

Diretrizes Curriculares Nacionais da Educação Básica - DCNEB / Ministério da Educação. Secretaria de Educação Básica. Diretoria de Currículos e Educação Integral. Brasília: MEC, SEB, DICEI, 2003.

FERNANDES, Claudia de Oliveira e FREITAS, Luiz Carlos de. "Currículo e Avaliação”. In: MOREIRA, Antônio Flávio e ARROIO, Miguel. Indagações sobre currículo. Brasília: Departamento de Políticas de Educação Infantil e Ensino Fundamental, nov. 2006, p. 113-137.

Lei de Diretrizes e Bases da Educação Nacional - LDB / Lei n 9394/96, de 20 de dezembro de $1996-11^{\text {a }}$ ed.

MOREIRA, Antônio Ferreira e Candau, Vera Maria, Educação Escolar e Cultura: construindo caminhos. Revista Brasileira de Educação. N. 23, p.156-168, 2003.

Plano Nacional de Educação - PNE / Lei no 13.005, de 25 de junho de 2014.

SILVA, T.T. da. Documentos de Identidade: uma introdução às teorias do currículo. 